\title{
CULTIVARES DE CAFÉ DE PORTE BAIXO ENXERTADOS E NÃO ENXERTADOS NAS CONDIÇÕES EDAFOCLIMÁTICAS DA ALTA PAULISTA
}

\author{
Maikon Vinicius da Silva Lira ${ }^{1}$
}

Fernando Takayuki Nakayama

Jorge Luiz Abranches ${ }^{3}$

\begin{abstract}
RESUMO
A cafeicultura na região da Alta Paulista tem atravessado sérias dificuldades técnicas e econômicas e muitos chegam a abandoná-la partindo para outras atividades agropecuárias. O manejo inadequado das lavouras, a falta de recursos financeiros e variedades adaptadas e resistentes a pragas e doenças são responsáveis por este cenário. O objetivo do presente trabalho é oferecer ao produtor da região novas opções de materiais genéticos melhorados de café de porte baixo, bem com compará-los em plantios enxertado e sem enxerto buscando a sustentabilidade produtiva. Instalou-se no município de Adamantina/SP dois experimentos com diversos materiais genéticos de café enxertados e não enxertados sendo conduzidos durante as safras de 2013 e 2014 no qual foram obtidos os dados de produtividade. Para o experimento de cafés enxertados, observou-se uma maior uniformidade produtiva dentre os materiais genéticos, sobretudo para a safra 2013; a safra 2014 apresentou maior variabilidade produtiva dentre os materiais testados nos 2 experimentos; para a situação enxertada, o material genético de café "Catuaí SH3 Faz. São José" foi o mais produtivo para as médias dos anos de 2013 e 2014; para a situação "pé franco" os materiais de café "Catuaí A IAC 62", "Catuaí V. IAC 99", "Catuaí A IAC 32", "Catuaí A IAC 86", "Ouro A IAC 4397" não demonstraram um bom desenvolvimento vegetativo, tampouco produtivo, não sendo indicados para a região Alta Paulista para sistema de plantio "pé franco".
\end{abstract}

Palavras-chave: Cafeicultura. Melhoramento genético. CafeeirosEnxertados.

\section{COFFEE VARIETIES GRAFTED AND NOT GRAFTED IN EDAPHOCLIMATIC CONDITIONOF ALTA PAULISTA}

\begin{abstract}
Coffee growing in the Alta Paulista region has experienced serious technical and economic hardship, and many come to abandon it leaving for other agricultural activities. Inadequate handling of crops, lack of financial resources and adapted and resistant to pests and diseases varieties account for this scenario. The aim of this work is to provide to the producer in the region, new options for improved genetic materials of coffee short stature, as well as compare them in planting grafted and ungrafted and grafted between Franco feet seeking productive sustainability. He settled in the town of Adamstown / SP 2 experiments with different genetic material grafted and grafted coffee not being
\end{abstract}

\footnotetext{
1 Engenheiro Agrônomo - SENAR-email - maikonvinicius@hotmail.com

2 Pesquisador Científico - Apta - PRDTA Alta Paulista, fnakayama@apta.sp.gov.br

${ }^{3}$ Engenheiro Agrônomo - Prefeitura Municipal Bauru
} 
conducted during the seasons of 2013 and 2014 in which productivity data were obtained. For the experiment of grafted cafes, there was greater uniformity among the productive genetic material, especially for the 2013 season; The 2014 season showed greater production variability among the materials tested in the two experiments; For grafted situation, the genetic material of coffee "Catuai SH3 Faz São José" was the most productive for the average of the years 2013 and 2014; To the situation "ungrafted" materials coffee Catuaí IAC 62, IAC Catuaí V. 99, Catuaí IAC 32, IAC Catuaí 86, 4397 Gold IAC did not show a good vegetative growth, nor productive, not being suitable for Alta Paulista region in planting "ungrafted".

Keywords: Coffee Production. Genetic improvement.GraftedCoffee.

\section{VARIEDADES DE CAFÉ TAMAÑO BAJO INJERTADOS Y NO INJERTADAS EN CONDICIONES EDAFOCLIMÁTICA DEL ALTA PAULISTA}

\section{RESUMEN}

El café en la región de Alta Paulista tiene pasado por serias dificultades técnicas y económicas y muchos vienen a abandonar la cafeicultura para otras actividades agrícolas. El manejo inadecuado de los cultivos, la falta de recursos financieros y de variedades adaptadas y resistentes a plagas y enfermedades representan para este escenario. El objetivo de este estudio es proporcionar al productor en la región, las nuevas opciones de materiales genéticos mejorados bajo tamaño de café, así como compararlos en plantación sin injertar y injertado que buscan la sostenibilidad productiva. Instalado en la ciudad de Adamantina/SP 2 experimentos con diferente material genético del café injertado y no injertado que se realizan durante los 2013 y 2014 las cosechas en la que se obtuvieron los datos de rendimiento. Para el experimento de cafés injertadas, se observó una mayor uniformidad de producción entre los materiales genéticos, especialmente para la cosecha de 2013; la cosecha de 2014 tuvo mayor variabilidad de la producción entre los materiales probados en dos experimentos; para la situación injertado, el material genético de café "Catuai SH3 faz. San José" fue el más productivo para el promedio de los años 2013 y 2014; A la situación de "pie franco" materiales de café"Catuaí IAC 62", "IAC Catuaí V. 99", "Catuaí IAC 32", "Catuaí IAC 86", "IAC Oro 4397" no mostró un buen desarrollo vegetativo, ni productivo y no es adecuado para región Alta Paulista en la plantación de "pie franco".

Palabras clave: Café Cultura. Mejoramiento genético. Café injertado.

\section{INTRODUÇÃO}

Nos dias atuais a cafeicultura vem atravessando dificuldades em vários aspectos, dentre os principais relacionados às práticas de manejo, dificuldades de combate a pragas, e problemas relacionados com organismos patogênicos, dos quais podem causar quedas de qualidade, produtividade inviabilizando uma agricultura sustentável. Neste contexto a cada dia o uso de defensivos agrícolas 
vem se tornando crescente e inevitável, o que muitas vezes conflita com aspectos relacionados aos riscos ambientais e de saúde.

Dentre os principais problemas relacionados às pragas, destacam-se bicho mineiro e os nematóides, ou, mais propriamente fitonematóides que são organismos vermiformes, que atacam o sistema radicular dos cafeeiros, comprometendo a absorção de água e nutrientes, podendo, assim, reduzir o desenvolvimento e a produtividade da lavoura. Este prejuízo está ligado a diversos fatores, como a espécie do nematóide, a variedade do café, o tipo de solo e a idade das plantas. Segundo Matielloet al. (2003), as espécies mais conhecidas e melhor estudadas, quanto aos problemas causados em cafezais, são aquelas formadoras de galhas, sendo destacadas: Meloidogyneincognita, M. paranaensis e M. exígua, dos quais provocam a degenerescência gradativa dos cafezais. Nestas lavouras, devido ao seu sistema radicular reduzido, a resposta à adubação e outros tratos é menor (Malavolta et al., 1986).

Quanto aos problemas relacionados às doenças, destaca-se a ferrugem alaranjada do cafeeiro, que é causada pelo fungo parasita HemileiavastatrixBerk. et $\mathrm{Br}$. e ocasiona perdas na produtividade das lavouras brasileiras em torno de $30 \%$, se nenhuma medida de controle for adotada (Kushalappa\&Eskes, 1989). Os prejuízos causados pela doença dependem das condições climáticas, do sistema de cultivo, do manejo da lavoura e da cultivar plantada (Zambolimet al., 2002). Entre as medidas de controle da ferrugem, a utilização de cultivares resistentes é a de mais fácil adoção, além de ser economicamente viável e não afetar o meio ambiente. Essa tecnologia possibilita ao produtor minimizar a utilização de produtos fitossanitários na lavoura cafeeira, contribuindo para o desenvolvimento de uma cafeicultura mais sustentável e competitiva. Porém cultivares resistentes à ferrugem disponibilizadas para cultivo comercial, ao longo do tempo, pode tornar-se suscetíveis a novas raças do patógeno, que se desenvolvem por meio de mutações genéticas, com potencial para superar a resistência de determinados cafeeiros. Portanto, o trabalho dos melhoristas têm sido constantes, no intuito de superar a patogenicidade das novas raças de $H$. vastatrix que surgem e, ao mesmo tempo, obter resistência mais duradoura à doença. 
Neste contexto, associada aos outros fatores relacionados às ações técnicas e políticas, a cafeicultura da região da Alta Paulista atravessa sérias dificuldades e muitos chegaram a abandoná-la partindo para outras atividades agropecuárias, haja visto o alto custo de produção associado à quedas na produtividade, causado pelo uso contínuo de insumos destacando os agroquímicos.

O desenvolvimento de cultivares resistentes e/ou tolerantes às pragas e doenças tem papel importante no aumento de produtividade e diminuição de custos de produção. Mesmo que haja defensivos para o controle, a aplicação pode não ser eficiente e o uso de cultivares resistentes é o método de controle mais eficiente e de menor custo, além de evitar a contaminação do ambiente e de trabalhadores rurais.

O presente trabalho tem o objetivo de avaliar a pratica da enxertia, sanando dúvidas sobre o desenvolvimento e produção relacionada a essa pratica, bem como avaliar novos matérias genéticos com resistências múltiplas, minimizando despesas relacionadas à uso incessante de defensivos agrícolas, consequentemente baixando custos de produção e buscando a sustentabilidade da presente cadeia produtiva para a região da Alta Paulista.

\section{MATERIAL E MÉTODOS}

\subsection{Período e localização de experimento}

O presente trabalho foi conduzido entre os anos agrícolas de 2012/2013 e 2013/2014, em área experimental pertencente à CAMDA (Cooperativa Agrícola

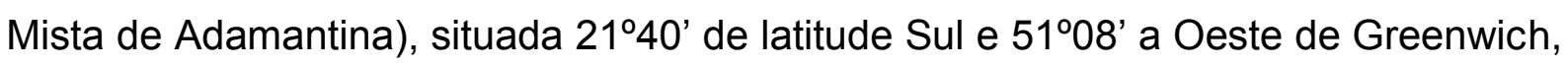
com altitude de 415 metros, no qual se instalou a Unidade de Avaliação e Demonstração (UAD) localizada às margens da Rodovia SP 294 (Comandante João Ribeiro de Barros), Adamantina/SP.

O solo do local é classificado como argissolo vermelho-amarelo, eutrófico a moderado, textura arenosa / média e apresenta uma topografia ondulada (EMBRAPA, 1999). O clima da região é do tipo Aw, com estação chuvosa e quente no verão e inverno seco, segundo a classificação de Köppen. A precipitação média 
anual é de $1324 \mathrm{~mm}$ com uma evapotranspiração média de $1176 \mathrm{~mm}$, sendo que na estação chuvosa há excedente de $233 \mathrm{~mm}$ e deficiência de 108,9 mm na estação seca, a temperatura média anual é de $22,6^{\circ} \mathrm{C}$ e a umidade relativa do ar entre $70 \mathrm{e}$ $80 \%$ (média anual).

O delineamento empregado foi o de blocos ao acaso com 4 repetições para os 2 experimentos, totalizando 92 parcelas com 10 plantas cada (23 materiais $\times 4$ repetições), no qual foram colhidas 5 plantas centrais de cada parcela.

Antes da instalação do experimento, realizou-se a coleta de amostra de solo da área experimental e realizada a análise química de acordo com metodologia proposta por Raijet al. (1987) e posteriormente a área foi submetida ao preparo convencional, calagem e adubação fornecida na cova, conforme recomendações de Adubação e Calagem para o Estado de São Paulo (RAIJ et al., 2001).

Para o controle de plantas daninhas foram realizadas capinas manuais no período inicial de desenvolvimento, durante os primeiros meses de condução do experimento. Em seguida seguiu o controle sendo realizado com a aplicação de herbicidas pré-emergentes e pós-emergentes registrados para a cultura do cafeeiro, com as doses recomendadas.

\subsection{Variável avaliada}

A variável avaliada no presente trabalho foi a produtividade de café beneficiado para os anos de 2013 e 2014. Para esta avaliação foram colhidas 5 plantas de cada parcela no ponto de maturação cereja, no qual foram pesados e secados em terreiro de alvenaria. Após a secagem foram pesados e foi obtido massa de café em coco. Para a obtenção da produtividade foi seguida a metodologia de MENDES (1941), citado por MENDES (1994), no qual obteve-se a conversão de peso de café da roça para produtividade (sacas de $60 \mathrm{~kg}$ de café beneficiado. ha $\left.^{-1}\right)$. Para realizar a conversão utilizou-se a seguinte formula: (produtividade $=\left[\left(\mathrm{kg} / \text { planta }^{*} 0,2\right)^{*} n^{\circ}\right.$ de plantas $\left./ \mathrm{ha}\right] / 60 \mathrm{~kg}$ ou seja rendimento em peso de $20 \%$ 
Volume 11, Número 02, 2015

Campo, Agronegócio e as Práticas Sustentáveis

\subsection{Análise dos dados}

Os dados obtidos no presente trabalho foram submetidos à análise de variância através do teste $\mathrm{F}$ e teste de comparação de médias (Tukey) ao nível de significância de 5\%, utilizando a metodologia descrita por Gomes (2000).

\subsection{Precipitação e temperatura nos anos de condução do experimento}

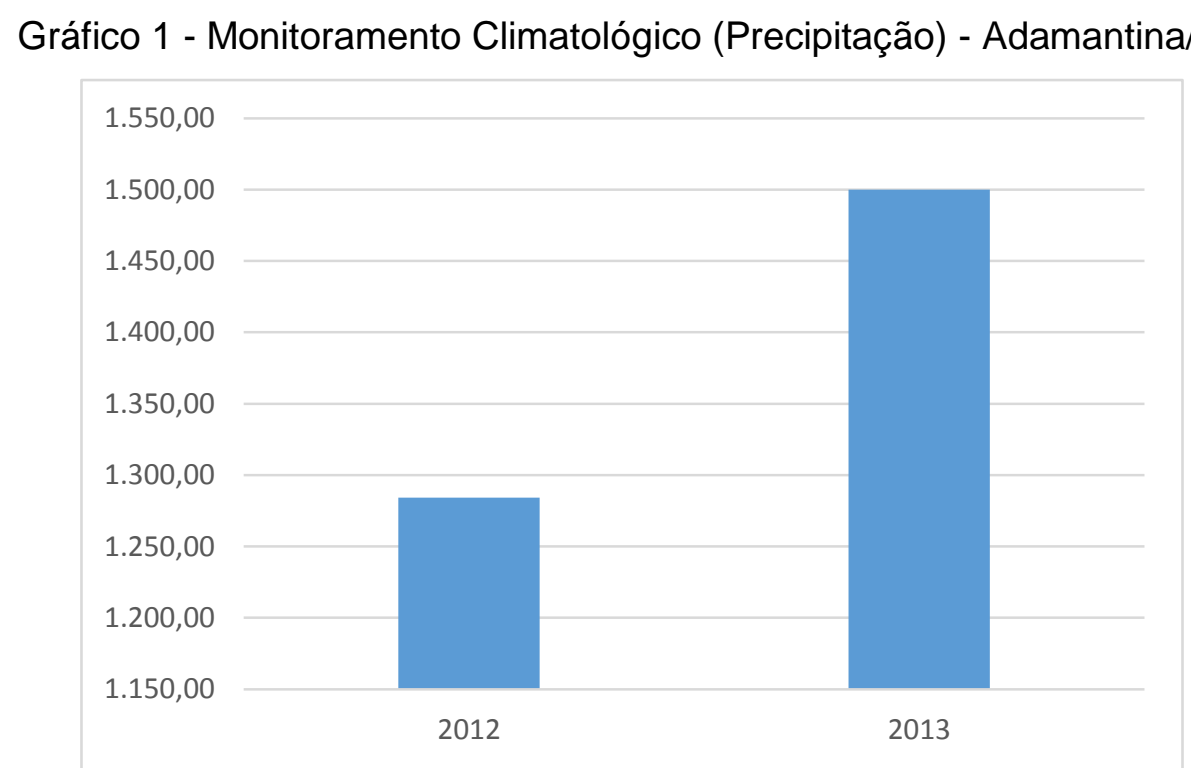

Fonte: http://www.ciiagro.sp.gov.br.

\section{RESULTADOS E DISCUSSÃO}

A tabela 01 apresenta os valores médios de produtividade de café de porte baixo enxertado (sacas.ha ${ }^{-1}$ ), obtidos em café beneficiado para os anos de $2013 \mathrm{e}$ 2014. Dentre os materiais genéticos testados, observamos uma variação considerável no aspecto visual de plantas, já que muitos provêm de regiões cafeeiras divergentes edafoclimaticamente da região da Alta Paulista, como é o caso de plantas que vieram do Cerrado Mineiro e Oeste Baiano. A safra de 2013 foi considerada a primeira safra, já que foram plantados em abril de 2011. Para os resultados obtidos em 2013, observa-se uma uniformidade na produtividade em relação à safra 2014, possivelmente devido ao fato de ser a primeira safra e também 
às condições climáticas de 2014 não favorecerem o desenvolvimento vegetativo destas plantas, haja visto os baixos índices de precipitação no período de verão (Gráfico 01). O café Catuaí SH3 Faz. São José, diferiu estatisticamente dos cafés Catuaí A. IAC 32, Catuaí A IAC 86, Obatã A IAC 4739, Icatu P.B. IAC 4553 C 355 e linhagens H 9081-5- C 1955 L 109, IAC 1669-31-1 C 1204 L 109, sendo o material

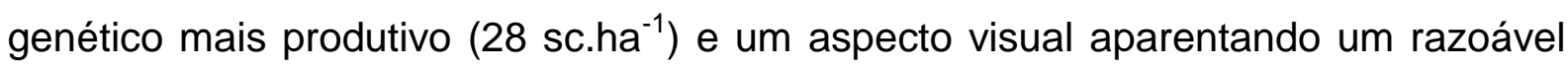
vigor vegetativo. Segundo Matielloet al.(2012), produtividade, bom vigor, arquitetura aberta, resistência à ferrugem e Phoma/Ascochyta e outras, maturação diferenciada (mais uniforme), tolerância à seca, boa capacidade de recuperação pós-poda são características que devem ser observadas na escolha de variedades de café, o que foi encontrado no Catuaí SH3 Faz. São José. Destaca-se ainda a presença do gene SH3 neste material genético. Este gene, Segundo Seraet al. (2007) foi descoberto por Noronha-Wagner and Bettencourt, 1967; Bettencourt and Noronha-Wagner, 1971; Bettencourt et al., onde estes autores identificaram resistência a raças de Hemileiavastatrix (ferrugem).

Para a safra 2014, observou-se uma grande variação nos valores médios de produtividade de café. Para este ano os materiais genéticos Obatã V IAC 1669-20 e a linhagemH 6839-5-1 C 1811 L 109 diferiram estatisticamente dos materiais Catuaí A IAC 62, Catuaí V. IAC 99, Catuaí A IAC 32, Catuaí A IAC 86, Ouro A IAC 4397, Tupi RN IAC 1669-13, IAC 5358, H 9081-5- C 1955 L 109 e H 15483 (F3) C 894 L 108, porém não diferiu dos materiais Obatã A IAC 4932 C 1241, Obatã A IAC 4739, H 13439-4- C(878+885+877), IAC 4934 R 10 PL 19, Catuaí SH3 Faz. São José, H 7316- C 987 L 109, Catuaí SH3 C 1610 L 108 e Icatu P.B. IAC 4553 C 355. Destacase às baixas produtividades dos materiais Catuaí $A$ IAC 62, Catuaí V. IAC 99, Catuaí A IAC 32, Catuaí A IAC 86 e H 15483 (F3) C 894 L 108. Deve-se atribuir o fato à má distribuição hídrica para esta safra, bem como a tradicional característica da bienalidade produtiva, relevante nos materiais citados. 
Tabela 01. Valores médios de produtividade de café de porte baixo enxertado (sacas. ha ${ }^{-1}$ ), obtidos em café beneficiado - Adamantina (SP), 2014

\begin{tabular}{|c|c|c|c|}
\hline & $\begin{array}{c}\text { Teste F } \\
\text { CV(\%) } \\
\text { DMS }\end{array}$ & $\begin{array}{c}0,0218 \\
33,48 \\
14,65\end{array}$ & $\begin{array}{c}0,00656 \\
40,83 \\
13,62\end{array}$ \\
\hline & Tratamentos & Produção2013 & Produção2014 \\
\hline 1 & Catuaí A IAC 62 & $16.20250 \mathrm{ab}$ & $5.2375 \mathrm{de}$ \\
\hline 2 & Catuaí V. IAC 99 & $14.03250 \mathrm{ab}$ & $5.4500 \mathrm{de}$ \\
\hline 3 & Catuaí A IAC 32 & $12.89000 b$ & $3.7675 \mathrm{e}$ \\
\hline 4 & Catuaí A IAC 86 & $12.80250 \mathrm{~b}$ & $3.6900 \mathrm{e}$ \\
\hline 5 & Ouro A IAC 4397 & $15.17250 \mathrm{ab}$ & $4.0275 \mathrm{e}$ \\
\hline 6 & Tupi RN IAC 1669-13 & $14.41250 \mathrm{ab}$ & 6.2400 cde \\
\hline 7 & Obatã V IAC 1669-20 & $19.52500 \mathrm{ab}$ & $23.4870 \mathrm{a}$ \\
\hline 8 & Obatã A IAC 4932 C 1241 & $18.20000 \mathrm{ab}$ & $21.63,50 \mathrm{ab}$ \\
\hline 9 & Obatã A IAC 4739 & $11.95750 \mathrm{~b}$ & 14.3875 abcde \\
\hline 10 & IAC 5358 & $15.55500 \mathrm{ab}$ & $5.7100 \mathrm{cde}$ \\
\hline 11 & H 13439-4- C(878+885+877) & $15.76750 \mathrm{ab}$ & $18.3025 \mathrm{abcd}$ \\
\hline 12 & IAC 4934 R 10 PL 19 & $19.38500 \mathrm{ab}$ & 15.8150 abcde \\
\hline 13 & H 6839-5-1 C 1811 L 109 & $13.49250 \mathrm{ab}$ & $23.7500 \mathrm{a}$ \\
\hline 14 & Catuaí SH3 Faz. São José & $28.07250 \mathrm{a}$ & 17.9800 abcde \\
\hline 15 & H 7316- C 987 L 109 & $18.73250 \mathrm{ab}$ & 16.4500 abcde \\
\hline 16 & H 9081-5- C 1955 L 109 & $10.36250 \mathrm{~b}$ & 9.2575 bcde \\
\hline 17 & H 13439-4- C 1738 L 109 & $18.62500 \mathrm{ab}$ & 12.2075 abcde \\
\hline 18 & IAC 1669-31-1 C 1204 L 109 & $12.22250 \mathrm{~b}$ & 10.4725 abcde \\
\hline 19 & Catuaí SH3 C 1639 L 108 & $17.00750 \mathrm{ab}$ & 12.9100 abcde \\
\hline 20 & H 15483 (F3) C 894 L 108 & $22.92250 \mathrm{ab}$ & $7.7675 \mathrm{cde}$ \\
\hline 21 & H 15497- C 506 L 108 & $18.75000 \mathrm{ab}$ & 12.8475 abcde \\
\hline 22 & Catuaí SH3 C 1610 L 108 & $19.61250 \mathrm{ab}$ & 17,1900 abcde \\
\hline 23 & Icatu P.B. IAC 4553 C 355 & $11.76750 \mathrm{~b}$ & $19,0950 \mathrm{abc}$ \\
\hline
\end{tabular}

As médias seguidas pela mesma letra não diferem estatisticamente entre si. Foi aplicado o Teste de Tukey ao nível de 5\% de probabilidade.

Os resultados dos valores médios de produtividade de café de porte baixo "pé franco" (sacas.ha ${ }^{-1}$ ), obtidos em café beneficiado em Adamantina (SP), 2013 e 2014 estão expressos na tabela 02. Uma importante observação para os materiais "pé franco" em relação aos enxertados é o fato de existir uma grande variação na produtividade para as 2 safras de cultivo. Atribui-se esta variação à possível existência de nematoides na área de cultivo, já que anteriormente, o histórico da área era de 30 anos de lavoura cafeeira. Este fato explica as baixas produtividades de alguns materiais genéticos, que provavelmente são mais 
susceptíveis à nematóides. Dentre eles os materiais CatuaíV. IAC 99, Catuaí $A$ IAC 32, H 7316- C 987 L 109, Catuaí SH3 C 1639 L 108 e Catuaí SH3 C 1610 L 108 produziram abaixo de 15,4 sacas por ha, bem abaixo da média para o ano. $O$ café Catuaí SH3 Faz. São José $(40,21$ sc.ha-1) novamente se comportou como o mais produtivo, mesmo na situção pé franco, diferindo significativamente dos demais materiais de catuaí,Obatã A IAC 4739, IAC 5358, H 7316- C 987 L 109, IAC 1669-31-1 C 1204 L 109 e do Catuaí SH3 C 1639 L 108. Para a safra 2014, estas diferenças se intensificaram, pois alem de alguns materiais apresentaremse susceptíveis à nematóides, ocorreram adversidades climáticas e a apresentação de expressiva bienalidade para alguns materiais. Dentre os materiais testados os cafés Catuaí A IAC 62, Catuaí V. IAC 99, Catuaí A IAC 32, Catuaí A IAC 86, Ouro A IAC 4397 produziram abaixo de 3,5 sc.ha-1, destacandose pela baixa produtividade e baixo vigor, possivelmente não sendo indicada para a região da Alta Paulista no plantio "pé franco". Os materiais genéticos de café Obatã V IAC 1669-20, H 9081-5- C 1955 L 109, H 13439-4- C 1738 L 109, IAC 1669-31-1 C 1204 L 109, H 15483 (F3) C 894 L 108, H 15497- C 506 L 108 e Icatu P.B. IAC 4553 C 355 foram os mais produtivos, porém com característica de inversão da bienalidade para alguns materiais. Ressalta-se que para a condução dos materiais genéticos "pé franco", além da bienalidade, as características climáticas desfavoráveis atribuídas à condução em área com histórico de nematóides pode explicar a grande variabilidade produtiva e contribuir para a indicação de materiais de café porte baixo para a região. Consideram-se os resultados do presente trabalho relevante para a cafeicultura regional, porém deve-se salientar que resultados de 2 anos de safra ainda são insuficientes para a indicação segura de materiais genéticos, haja visto a longevidade de uma cultura cafeeira. Neste sentido é importante que a condução do presente trabalho ainda continue por pelo menos 5 safras, para assegurar uma indicação fitotécnica de materiais de café de porte baixo. 
Tabela 2. Valores médios de produtividade de café de porte baixo "pé franco" $\left(\right.$ sacas. ha $\left.{ }^{-1}\right)$, obtidos em café beneficiado - Adamantina (SP), 2013 e 2014.

\begin{tabular}{|c|c|c|c|}
\hline & $\begin{array}{c}\text { Teste F } \\
\text { CV (\%) } \\
\text { DMS }\end{array}$ & $\begin{array}{c}6,05 \text { ** } \\
33,47 \\
19,20\end{array}$ & $\begin{array}{c}11,16^{\star \star} \\
34,54 \\
11,54\end{array}$ \\
\hline & Tratamentos & Produção 2013 & Produção 2014 \\
\hline 1 & Catuaí A IAC 62 & 19.73750 bcde & $3.54500 \mathrm{e}$ \\
\hline 2 & Catuaí V. IAC 99 & $15.24000 \mathrm{e}$ & $3.12250 \mathrm{e}$ \\
\hline 3 & Catuaí A IAC 32 & $11.91500 \mathrm{e}$ & $2.75250 \mathrm{e}$ \\
\hline 4 & Catuaí A IAC 86 & $17.99000 \mathrm{cde}$ & $3.44000 \mathrm{e}$ \\
\hline 5 & Ouro A IAC 4397 & 22.66750 abcde & $2.59000 \mathrm{e}$ \\
\hline 6 & Tupi RN IAC 1669-13 & $37.86250 \mathrm{abc}$ & $8.19750 \mathrm{cde}$ \\
\hline 7 & Obatã V IAC 1669-20 & 30.25250 abcde & $23.91000 \mathrm{ab}$ \\
\hline 8 & Obatã A IAC 4932 C 1241 & 25.80000 abcde & 13.64750 bcde \\
\hline 9 & Obatã A IAC 4739 & 19.07000 bcde & $10.58000 \mathrm{cde}$ \\
\hline 10 & IAC 5358 & 17.87500 cde & $4.49750 \mathrm{de}$ \\
\hline 11 & H 13439-4- C(878+885+877) & 31.85250 abcde & $9.99750 \mathrm{cde}$ \\
\hline 12 & IAC 4934 R 10 PL 19 & $35.77000 \mathrm{abcd}$ & 12.75000 bcde \\
\hline 13 & H 6839-5-1 C 1811 L 109 & 30.47750 abcde & $12.4 \mathrm{bc} 85000 \mathrm{bcde}$ \\
\hline 14 & Catuaí SH3 Faz. São José & $40.21000 \mathrm{a}$ & $16.61000 \mathrm{bc}$ \\
\hline 15 & H 7316- C 987 L 109 & $12.11750 \mathrm{e}$ & 13.91250 bcde \\
\hline 16 & H 9081-5- C 1955 L 109 & $16.88000 \mathrm{de}$ & $28.77750 \mathrm{a}$ \\
\hline 17 & H 13439-4- C 1738 L 109 & $38.64750 \mathrm{ab}$ & $18.41000 \mathrm{abc}$ \\
\hline 18 & IAC 1669-31-1 C 1204 L 109 & $16.23750 \mathrm{de}$ & $18.24250 \mathrm{abc}$ \\
\hline 19 & Catuaí SH3 C 1639 L 108 & $15.38500 \mathrm{e}$ & $9.52250 \mathrm{cde}$ \\
\hline 20 & H 15483 (F3) C 894 L 108 & $37.47750 \mathrm{abc}$ & $19.15250 \mathrm{abc}$ \\
\hline 21 & H 15497- C 506 L 108 & 25.73750 abcde & $18.88750 \mathrm{abc}$ \\
\hline 22 & Catuaí SH3 C 1610 L 108 & $15.27000 \mathrm{e}$ & $15.23250 \mathrm{bcd}$ \\
\hline 23 & Icatu P.B. IAC 4553 C 355 & 24.23000 abcde & $17.82750 \mathrm{abc}$ \\
\hline
\end{tabular}

As médias seguidas pela mesma letra não diferem estatisticamente entre si. Foi aplicado o Teste de Tukey ao nível de 5\% de probabilidade.

\section{CONCLUSÕES}

Para o experimento de cafés enxertados, observou-se uma maior uniformidade produtiva dentre os materiais genéticos, sobretudo para a safra 2013.

A safra 2014 apresentou maior variabilidade produtiva dentre os materiais testados nos dois experimentos. 
Para a situação enxertada, o material genético de café Catuaí SH3 Faz. São José foi o mais produtivo para a média dos anos de 2013 e 2014.

Para a situação "pé franco" os materiais de café Catuaí A IAC 62, Catuaí V. IAC 99, Catuaí A IAC 32, Catuaí A IAC 86, Ouro A IAC 4397 não demonstraram um bom desenvolvimento vegetativo, tampouco produtivo, não sendo indicada para a região no plantio "pé franco".

\section{REFERÊNCIAS}

EMPRESA BRASILEIRA DE PESQUISA AGROPECUÁRIA - EMBRAPA. Sistema brasileiro de classificação de solos. Centro nacional de pesquisa de solos. Rio de Janeiro, 1999, 412p.

GOMES, P.F. Curso de estatística experimental, Piracicaba: USP, 2000. 477p.

KUSHALAPPA, A.C. \& ESKES, A.B. Coffee Rust: epidemiology, resistance and management. Boca Raton. CRC Press. 1989.

MALAVOLTA, E., RENA, A.B., ROCHA, M., YAMADA, T. Cultura do Cafeeiro - fatores que afetam a produtividade. Piracicaba SP. 1986.

MATIELLO J.B., JAPIASSU L.B., CARVALHO M.L., ROSA G.N., NematóideM. exigua prejudica renovação de cafezais. In: Anais 29ํㅡㄹC, Mapa/Procafé, 2003, p. 85-6. Disponível em: <http://fundacaoprocafe.com.br/downloads/Folha030Nematoide.pdf>. Acesso em 25 mai. 2015.

MATIELLO, ALMEIDA, CARVALHO. Indicação de novas variedades de café. Curso. Procafé 2012. Varginha-MG, 2012.

MENDES, A.N.G. Avaliação de metodologias empregadas na seleção de progênies do cafeeiro (Coffeacarabica L.) no estado de Minas Gerais. 1994. 167f. Tese (Doutorado em Fitotecnia) Universidade Federal de lavras, Lavras, 1994.

RAIJ, B. van; QUAGGIO, J. A.; CANTARELLA, J.; FERREIRA, M. E.; LOPES, A. S.; BATAGLIA, O. A. Análise química do solo para fins de fertilidade. Campinas: Fundação Cargill, 1987. 170 p.

RAIJ B. Van; ANDRADE, J. C.; CANTARELA, H.; QUAGGIO, J. A. - Análise Química para fertilidade de solos tropicais 1ª Edição, INSTITUTO AGRONOMICO - FUNDAÇÃO IAC, 2001. 285p.

SERA G.H., SERA T., ITO D.S., AZEVEDO J.A., MATA J.S., DOI D.S., RIBEIRO FILHO C., KANAYAMA F.S. Resistance to Leaf Rust in Coffee Carrying SH3 Gene and others SH Genes. Brazilian archive of biology and technology - an International journal. Brazil, Vol.50, n. 5 p. 753-757, 2007.

ZAMBOLIM, L.; VALE, F.X.R.; COSTA, H.; PEREIRA, A.A.; CHAVES, G.M.Epidemiologia e controle da ferrugem do cafeeiro (HemileiavastatrixBerk. et Br.). In:ZAMBOLIM, L. (Ed.). O Estado da Arte de Tecnologias na Produção de Café.Viçosa: Suprema Gráfica e Editora, 2002. p.369-433. 